\title{
A NOVEL COMPARATIVE CHROMATOGRAPHIC RESEARCH OF SECOIRIDOID GLYCOSIDES IN TWO SPECIES OF CENTAURY HERB
}

\author{
Svitlana Gubar, Anna Materiienko, Liudas Ivanauskas, Volodymyr Mishchenko, \\ Olha Vasylieva, Victoriya Georgiyants
}

\begin{abstract}
The aim: A novel comparative analysis of the secoiridoid glycosides composition in Centaurium erythraea Rafn. and Centaurium pulchellum (Sw.) Druce has being described. Swertiamarin has been chosen as an active marker and its comparative quantitative estimation in two species of the raw material has been carried out by HPLC method.

Materials and methods: The quantitative HPLC analysis of swertiamarin was conducted using a chromatographic column ACE 5 C18. Methanol and 0,5\% acetic acid aqueous solution were used as mobile phases; the chromatographic procedure was carried out in a gradient mode.

Results: The content of swertiamarin in the C. pulchellum herb ranges from 2.51 to $3.07 \mathrm{mg} / 100 \mathrm{mg}$. In that time swertiamarin content in C. erythraea herb varies and depends from 3.83 to $8.94 \mathrm{mg} / 100 \mathrm{mg}$. The content of swertiamarin in C. pulchellum herb is much lower than in C. erythraea herb. Taking into account this fact the possibility of using of $C$. pulchellum herb for medicine instead of C. erythraea herb must be proven additionally by biological experiments. Also it could be preliminary concluded that the most appropriate climate for swertiamarin accumulation in $C$. erythraea herb is located in Central and Eastern parts of Ukraine.

Conclusions: It was discovered that the main representative of secoiridoid glycosides in C. erythraea is swertiamarin when in C. pulchellum Druce that are represented by both sweroside and swertiamarin. A more perspective raw material -C. erythraea herb, according to the content of swertiamarin, was chosen
\end{abstract}

Keywords: Centaurium erythraea, Centaurium pulchellum, secoiridoid glycosides, swertiamarin, HPLC, validation

How to cite:

Gubar, S., Materiienko, A., Ivanauskas, L., Mishchenko, V., Vasylieva, O., Georgiyants, V. (2021). A novel comparative chromatographic research of secoiridoid glycosides in two species of centaury herb. ScienceRise: Pharmaceutical Science, 3 (31), 29-34. doi: http://doi.org/10.15587/25194852.2021 .235774

(C) The Author(s) 2021

This is an open access article under the Creative Commons CC BY license

\section{Introduction}

Centaurium erythraea Rafn. (Gentianaceae) is widespread medicinal plant which is renowned for their bitter properties. Except this plant Centaury genus contains about 50 more species prevalent in Eurasia, South and North America and in Australia [1]. Among them seven Centaury species grow in Ukraine: Centaurium erythraea Rafn. (C. umbellatum Gilib., C. Minus Moench); Centaurium pulchellum (Sw.) Druce; Centaurium spicatum (L) Fritsch; Centaurium meyeri (Burge) Druce; Centaurium tenuiflorum (Hoffmsg. et Link) Fritsin; Centaurium littorale (D. Turner Gilmour); Centaurium uliginosum (Waldst.et Kit.).

C. erythraea herb is included into some world pharmacopoeias, such as European Pharmacopoeia (Eur.Ph.), German Pharmacopoeia (DAB 10), British Herbal Pharmacopoeia and State Pharmacopoeia of Ukraine ( $\mathrm{SPhU})$ as official herbal material (HM) named as Centaury.

Secoiridoid glycosides in Centaury herb are among the main biologically active substances (BAS) classes. Due to their presence this raw material has a bitter flavor [2]. That is why Centaury herb is widely used for treating gastrointestinal diseases [3, 4]. Its gastroprotective [5], hepatoprotective, diuretic effects and hypoglycemic activity [6] and other medical activities have been described before [7]. The main representatives secoiridoid glycosides in Centaury herb are swertiamarin, gentiopicroside and - sweroside [8, 9] (Fig. 1).

Centaurium pulchellum (Sw.) Druce was described in the USSR Pharmacopoeia XIth ed. and Hungarian Pharmacopeia IIIrd ed. as officially substitute HM for $C$. erythraea. However, $C$. pulchellum has not been included into other world pharmacopeias as an official HM [10]. While the C. erythraea grows throughout Ukraine, the $C$. pulchellum grows only in certain climatic zones in a limited area. Taking into account the climatic conditions of their growth the study of the chemical composition of different centaury species, is very relevant in order to find a new, promising HM.

The aim of the work was: comparative studying the chemical composition of secoiridoid glycosides in two species of Centaury herb - Centaurium erythraea Rafn. and Centaurium pulchellum (Sw.) Druce and development and validation of HPLC method for a quantitative analysis of 
swertiamarin in C. erythraea and C. pulchellum with the further assessment of the swertiamarin content in both Centaury species from different areas of Ukraine.<smiles>C=CC1C(O[SiH3])OCC2C(=O)OCC[C@@]21O</smiles>

$a$

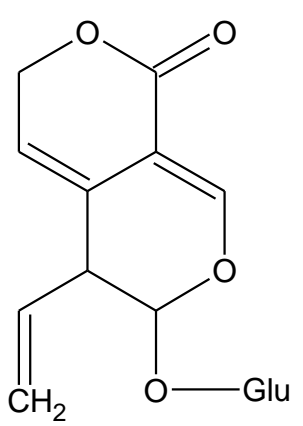

b<smiles>C=CC1C(OCl)OC=C2C(=O)OCC[C@@H]21</smiles>

$c$

Fig. 1. Chemical structures of secoiridoid glycosides: $a$-swertiamarin; $b$ - gentiopicroside; $c$-sweroside

\section{Research planning (methodology)}

For the quality assessment of $C$. erythraea herb EP do not require to estimate content of secoiridoid glycosides but "Bitterness value" test is carried out [11]. This method is based on a subjective estimation and taste receptor sensibility of the experts. This method has an insufficient repeatability of the results and does not allow to determine the bitterness content accurately also as a ratio of secoiridoid glycosides in HM. In addition, it should be noted that representatives of secoiridoid glycosides have different bitterness values [12]. So bitterness value test does not allow assessing objectively the composition and the content of secoiridoid glycosides in the HM.

According to previous studies, the most important representative of secoiridoid glycosides is swertiamarin. The main pharmacological actions of Centaury herb correlates with its presence [13]. Based on this, as well as on the recommendations of the European Pharmacopoeia, swertiamarin can be used as an active marker for the standardization of Centaury HM.

Earlier we have carried out a set of studies on developing a monograph of the SPhU "Centaury herb" using the approaches of the EP. According to the preliminary research, secoiridoid glycosides have been identified using a thin layer chromatography method [14]. Based on the "Bitterness value" test, it has become known that the general content of secoiridoid glycosides in these two species of HMs is comparable [15], however, this method does not allow estimate a content of the secoiroidoid glycosides in the analyzed HM. Based on this HPLC method can be chosen for the quantitative assessment of the secoiridoid glycosides content in two species of Centaury herb. At the first stage of our study we developed a new HPLC method. The second stage of the study was to establish the quantitative assessment of the secoiridoid glycosides content in two species of Centaury herb. At the third stage the developed HPLC method was validated and the fourth stage involved the quantitative estimation of swertiamarin in two species of Centaury herb due to differences in climatic conditions in different parts of Ukraine.

\section{Materials and Methods \\ Plant material}

Herb of C. erythraea (CE) and C. pulchellum (CP) were collected during flowering from June to July in different regions of Ukraine: Volyn region (BD CP 12701; BD CE 12712), Ivano-Frankivsk region (BD CP 12702), Zakarpattia region (BD CP 12703), Sumy region (BD CE 12704), Dnepr region (BD CE 12705), Lviv region (BD CE 12706; BD CE 12707), Kyiv region (BD CE 12708), Poltava region (BD CE 12709; BD CE 12710), Rivne region (BD CE 12711), Kharkiv region (BD CE 12713). For analytical studies, dried HM were ground into powder. Macroscopic and microscopic identification of HM has been carried out at the Department of Botany of the National University of Pharmacy. The plant species have been deposited in the herbarium section of the Botany Department in National University of Pharmacy, Ukraine.

\section{Reagents}

All the following reagents and solvents used were of analytical grade: methanol (Sigma-Aldrich); acetonitrile (Sigma-Aldrich); glacial acetic acid (Fluka). Chromatographic grade water was produced using a Milli-Q System (Millipore, Milan, Italy). Reference standard of swertiamarin (the purity - 99.5\%) produced by «Carbosynth» (UK) wasalso used.

\section{(HPLC)}

High performance liquid chromatography

Analysis was performed using a Waters Alliance 2690 HPLC Separations Module (Waters, Milford, USA), equipped with a diode array detector (996 PDA) and a chromatographic column ACE 5 C18 with particle size of 5 um $(250 \times 4,6 \mathrm{~mm})$ with a pre-column. The chromatographic conditions: a mobile phase A - methanol, a mobile phase $\mathrm{B}-0.5 \%$ acetic acid aqueous solution. The chromatography was carried out by the following gradient program:

$0-40 \min 95 \rightarrow 40 \% \mathrm{~A}, 5 \rightarrow 60 \% \mathrm{~B}$;

$40-41 \min 40 \rightarrow 10 \% \mathrm{~A}, 60 \rightarrow 90 \% \mathrm{~B}$;

$41-55 \min 10 \% \mathrm{~A}, 90 \% \mathrm{~B}$;

$55-56$ min $10 \rightarrow 95 \% \mathrm{~A}, 90 \rightarrow 5 \% \mathrm{~B}$;

$56-60 \min 95 \%$ A, $5 \%$ B.

The flow rate $-1 \mathrm{ml} / \mathrm{min}$, the injection volume $10 \mu \mathrm{l}$, detection at the wavelength of $238 \mathrm{~nm}$, the column temperature $-25^{\circ} \mathrm{C}$.

Preparation of the standard and test solutions

The standard solution of swertiamarin was prepared in concentration of $0.4 \mathrm{mg} / \mathrm{ml}$ by dissolving of the accurately weighed amount of swertiamarin standard in methanol immediately before using. The solution is filtered through a $0.45 \mu \mathrm{m}$ membrane filter before injection.

Also 5 calibrating solutions from the reference solution were prepared (swertiamarin concentration $-0.4 \mathrm{mg} / \mathrm{ml}$ ) 
by means of a stepwise dilution doubly: $0.2 \mathrm{mg} / \mathrm{ml}$, $0.1 \mathrm{mg} / \mathrm{ml}, 0.05 \mathrm{mg} / \mathrm{ml}, 0.025 \mathrm{mg} / \mathrm{ml}, 0.0125 \mathrm{mg} / \mathrm{ml}$.

Test solution: $0.5 \mathrm{~g}$ powdered HM (355 $\mu \mathrm{m}$, EP 2.9.12) was extracted with $15 \mathrm{ml}$ methanol and sonicated for 5 minutes at room temperature three times. The extracts were combined into a $50 \mathrm{ml}$ volumetric flask, made up to the mark with methanol and mixed. The solution obtained was filtered through a $0.45 \mu \mathrm{m}$ membrane filter before injection.

\section{Method validation}

The HPLC method was validated according to the ICH guidelines [16], SPhU requirements 5.3.N.2 [17] and following the standard validation procedure for quantitative analysis by a standard method. Validation parameters such as accuracy, precision and linearity were studied for the developed method for quantitative determination of swertiamarin in HM. To confirm these parameters, 5 model solutions were prepared, the concentration of which varied uniformly within the range 50-250 \% (from $0.4 \mathrm{mg} / \mathrm{ml}$ to $0.0125 \mathrm{mg} / \mathrm{ml}$ ). The intermediate precision of the assay method was also evaluated using six test solutions analyzed by different analyst on different days during one week and various measuring glassware.

Linear relationship parameters have been calculated for model solutions by a least square fit method: an absolute term a, residual standard deviation, correlation coefficient. To estimate accuracy and precision within the application range bounds of the analytical method, 5 test solutions were prepared, in line with all the stages of the analytical method. Swertiamarin concentration in the solutions ranged from $0.32 \mathrm{mg} / \mathrm{ml}$ to $0.01 \mathrm{mg} / \mathrm{ml}$.

\section{Results}

Different approaches to the quantitative estimation of individual representatives of secoiridoid glycosides or the sum of these compounds are described [18].
Among them analysis of gentiopicroside in C. erythraea $[19,20]$ and swertiamarin in other spices of $\operatorname{HM}[21,22]$ were studied.

To study the composition of secoiridoid glycosides in two species of Centaury herb we have developed a new HPLC method. When developing the method, we have studied all the described approaches to the analysis of secoiridoid glycosides [23] and explored the detection wavelength, different solvent systems and the compositions of mobile phase. According to preliminary results, the detection wavelength of $238 \mathrm{~nm}$ and the mixture of methanol and $0.5 \%$ acetic acid aqueous solution as mobile phases at gradient program elution were chosen.

Secoiridoid glycosides identification was carried out by comparing of the absolute and relative retention times, and also by comparing the UV spectra of the substances analyzed. The relative retention time of swertiamarin was accepted as 1.0 (absolute retention time $19.7 \mathrm{~min}$ ): so calculated relative retention time of gentiopicroside is 1.09 (absolute retention time $21.5 \mathrm{~min}$ ) and sweroside - 1.15 (absolute retention time $22.7 \mathrm{~min}$ ).

According to preliminary results we can see that there is a difference in the composition of secoiridoid glycosides in the studied Centaury species. Thus C. erythraea herb mainly contains two secoiridoid components swertiamarin and gentiopicroside, when sweroside also was found but in a trace amount (Fig. 2).

Preliminary content of gentiopicroside is much lower than that one for swertiamarin. Analyzing the chromatograms of the $C$. pulchellum test solutions, it should be noted that besides swertiamarin and gentiopicroside, it contains a significant amount of sweroside (Fig. 3). Thus the main representative of secoiridoid glycosides in C. erythraea herb is swertiamarin when in $C$. pulchellum herb are both sweroside and swertiamarin.

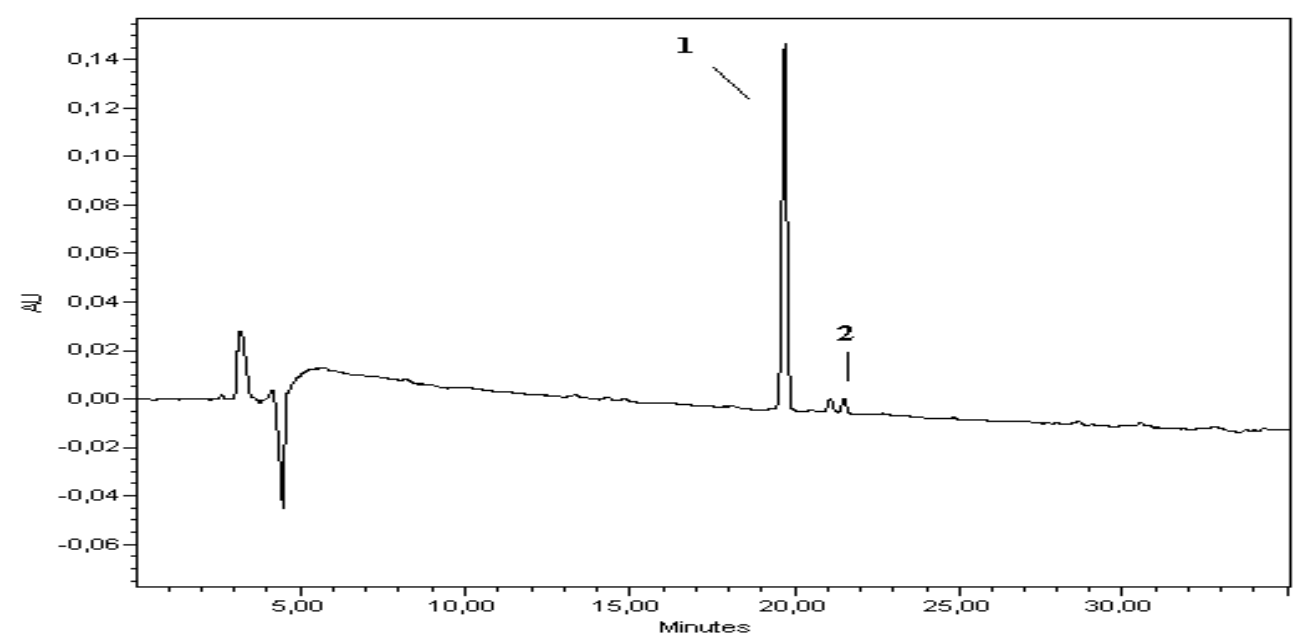

Fig. 2. Chromatogram of C. erythraea . herb test solution by HPLC method: 1 - swertiamarin, 2 - gentiopicroside 


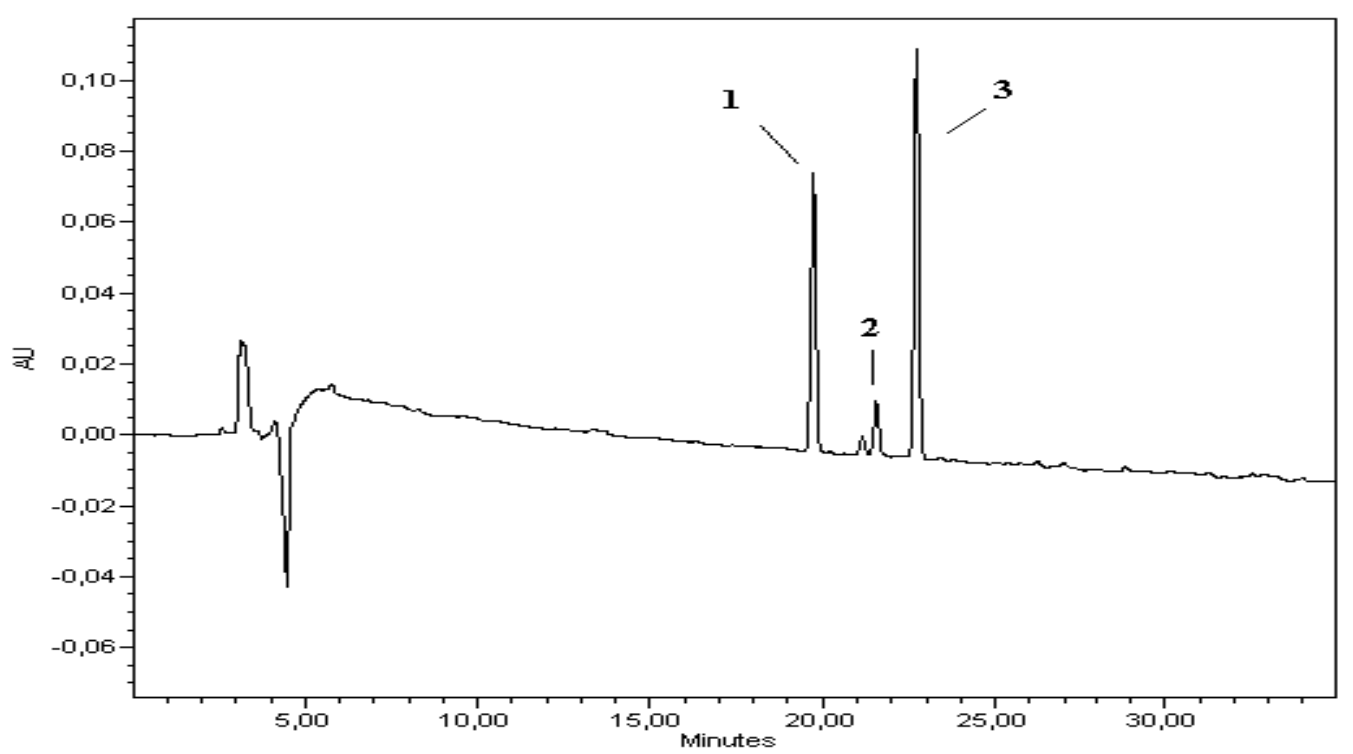

Fig. 3. Chromatogram of $C$. pulchellum herb test solution by HPLC method: 1 - swertiamarin, 2 - gentiopicroside, 3 - sweroside

According to the preliminary research results, both Centaury species HM contain swertiamarin in a significant amount. Due to this fact and data about its pharmacological and biological potential [2] it has been chosen as an active marker for estimating BAS content.

For quantitative estimation of swertiamarin the developed before HPLC method was validated (Table 1).

The obtained results prove that swertiamarin quantitative estimation method by a HPLC method is linear. The developed method satisfies the acceptability criteria of validation indices "Accuracy", "Precision" and "Intermediate precision".

The obtained results (Table 2) showed that the content of swertiamarin in the $C$. pulchellum herb ranges from 2.51 to $3.07 \mathrm{mg} / 100 \mathrm{mg}$. In that time swertiamarin content in C. erythraea herb varies and depends from 3.83 to $8.94 \mathrm{mg} / 100 \mathrm{mg}$. The highest swertiamarin content $(8.94 \pm 0.32$ and $8.32 \pm 0.32)$ was in samples from Poltava region (Central Ukraine) while the lowest - in samples from Sumy (b. 4), Lviv (bb. 6, 7) and Rivne (b.11) regions.

Table 1

The results of validation parameters assessment

\begin{tabular}{|c|c|c|c|}
\hline Parameters & Requirements, $\%$ & Reported value, $\%$ & Criterion satisfaction \\
\hline$\Delta_{\mathrm{As}} \%$ & $\leq 6.4$ & 2.89 & Satisfied \\
\hline$|a|$ & $\leq 10.2$ & 1.7964 & Satisfied \\
\hline $\mathrm{S}_{0}$ & $\leq 3.4$ & 1.05 & Satisfied \\
\hline $\mathrm{r}$ & $>0.9691$ & 1.0000 & Satisfied \\
\hline $\mid \bar{Z}-100$ & $\leq 1.06$ & 1.98 & Satisfied against the second criterion \\
\hline$\Delta \mathrm{Z}$ & $\leq 2.048$ & 2.24 & Satisfied \\
\hline$\Delta_{\text {intra }}$ & $\leq 6.4$ & 0.298 & Satisfied \\
\hline
\end{tabular}

Table 2

The results of estimating swertiamarin quantitative content in Centaury herb samples

\begin{tabular}{|c|c|c|c|c|c|}
\hline \multirow{2}{*}{ Batch № } & $\begin{array}{c}\mathrm{X}_{\mathrm{avg}} \pm \Delta \mathrm{x}, \\
\mathrm{mg} / 100 \mathrm{mg}\end{array}$ & Batch № & $\begin{array}{c}\mathrm{X}_{\mathrm{avg}} \pm \Delta \mathrm{x}, \\
\mathrm{mg} / 100 \mathrm{mg}\end{array}$ & Batch № & $\begin{array}{c}\mathrm{X} \\
\mathrm{avg}\end{array}$ \\
\hline \multirow{2}{*}{1} & $2.51 \pm 0.19$ & 4 & $4.80 \pm 0.33$ & 9 & $8.94 \pm 0.32$ \\
\cline { 2 - 6 } & $2.55 \pm 0.19$ & 5 & $7.26 \pm 0.17$ & 10 & $8.32 \pm 0.32$ \\
\hline 2 & \multirow{2}{*}{$3.07 \pm 0.43$} & 7 & $3.83 \pm 0.42$ & 11 & $5.14 \pm 0.24$ \\
\cline { 2 - 6 } & & 8 & $5.15 \pm 0.24$ & 12 & $7.22 \pm 0.31$ \\
\hline
\end{tabular}

\section{Discussion}

The use of medicinal plants has not lost its relevance, however, wild-growing raw materials are prone to reduction. Earlier in the literature, it was described the study of the conditions for the cultivation of these types of raw materials, however both Centaury species are wild plants and are not cultivated in Ukraine [24]. Also, the literature describes the chemical composition $C$. erythraea herb [8] in general, but the study of the dependence of the amount of secoiridoid glycosides, namely, svertiamarin, in the raw 
material, depending on the climatic conditions of its growth, was carried out by us for the first time. In addition, we carried out a more detailed analysis of the qualitative analysis of securidoid glycosides in C. pulchellum herb.

Due to great differences in climatic conditions in different parts of Ukraine content of secoiridoid glycosides can depend on collection area. Thus it was very important to study the swertiamarin content in two species of Centaury herb collected at different areas of Ukraine. So we use samples of $C$. pulchellum, collected at 3 regions of the Western Ukraine (batches 1-3) because its limited growing area. Samples of $C$. erythraea herb were collected from different areas as Northern (batch 4), Eastern (batches 5, 13), Central (batches 8-10) and Western (batches 6, 7, 11, 12) Ukraine. HPLC method developed has been used for comparative assessment of the swertiamarin content as main secoiridoid glycoside in the samples of Centaury species HM.

As a result it can be concluded that in general the content of swertiamarin in C. pulchellum herb is much lower than in C. erythraea herb. Taking into account this fact the possibility of using of $C$. pulchellum herb for medicine instead of $C$. erythraea herb must be proven additionally by biological experiments. Also it can be preliminary concluded that the most appropriate climate for swertiamarin accumulation in $C$. erythraea herb is located in Central and Eastern parts of Ukraine.

Study limitations. The obtained results can be used to assert that the quantitative content of swertiamarin in C. pulchellum herb is significantly lower than that in $C$. erythraea herb, but they do not completely confirm these assumptions and they cannot be the reason for prohibiting the use of this type of raw material.

Prospects for further research. Despite the fact that the content of svertiamarin differs significantly, the possibility of using $C$. pulchellum herb in medicine cannot be ruled out. A promising direction is to conduct further biological research, the results of which will be able to establish requirements for the quality of raw materials when using it for medical purposes.

In addition to biological experiments, the obtained results will be used in the study of optimal conditions for the cultivation of Centaury species in Ukraine.

\section{Conclusions}

A novel comparative analysis of a chemical composition of secoiridoid glycosides in two species of Centaury herb: Centaurium erythraea Rafn. and Centaurium pulchellum (Sw.) Druce was carried out. As follows from the analysis, the main representative of secoiridoid glycosides in C. erythraea is swertiamarin and for $C$. pulchellum they are sweroside and swertiamarin.

Based on the results of the conducted studies, swertiamarin, contained in two HM species, has been chosen as a marker substance, and a method of its quantitative estimation by HPLC has been developed. The developed method has been validated. All the parameters meet the acceptability criteria.

Swertiamarin quantitative content in C. erythraea and $C$. pulchellum has been analysed and it has been determined that the content of swertiamarin in C. pulchellum is in the range from 2.51 to $3.07 \mathrm{mg} / 100 \mathrm{mg}$, and in C. erythraea - from 3.83 to $8.94 \mathrm{mg} / 100 \mathrm{mg}$. As a result it can be concluded that in general the content of swertiamarin in C. pulchellum herb is much lower than in C. erythraea herb. Taking into account this fact the possibility of using of $C$. pulchellum herb for medicine instead of $C$. erythraea herb must be proven additionally by biological experiments. Also it can be preliminary concluded that the most appropriate climate for swertiamarine accumulation in $C$. erythraea herb is located in Central and Eastern parts of Ukraine.

Based on the conducted research, the presence and ratio of secoiridoid glycosides representatives such as swertiamarin, gentiopicroside and sweroside in Centaurium erythraea Rafn. and Centaurium pulchellum (Sw.) Druce was shown for the first time and a comparative assessment of the swertiamarin content in both Centaury species from different regions of Ukraine was carried out.

\section{Conflict of interests}

The authors declare that they have no conflict of interests.

\section{Financing}

The study was performed without financial support.

\section{References}

1. Siler, B., Misic, D. (2016). Chapter 11 - Biologically Active Compounds from the Genus Centaurium s.l. (Gentianaceae): Current Knowledge and Future Prospects in Medicine Studies in Natural Products Chemistry. Elsevier, 49, 363-397. doi: http://doi.org/10.1016/ b978-0-444-63601-0.00011-9

2. Petropoulos, S. A., Karkanis, A., Martins, N., Ferreira, I. C. F. R. (2018). Halophytic herbs of the Mediterranean basin: An alternative approach to health. Food and Chemical Toxicology, 114, 155-169. doi: http://doi.org/10.1016/j.fct.2018.02.031

3. Hamza, N., Berke, B., Cheze, C., Marais, S., Lorrain, S., Abdouelfath, A. et. al. (2015). Effect of Centaurium erythraea Rafn, Artemisia herba-alba Asso and Trigonella foenum-graecum L. on liver fat accumulation in C57BL/6J mice with high-fat diet-induced type 2 diabetes. Journal of Ethnopharmacology, 171, 4-11. doi: http://doi.org/10.1016/j.jep.2015.05.027

4. Stefkov, G., Miova, B., Dinevska-Kjovkarovska, S., Stanoeva, J. P., Stefova, M., Petrusevska, G., Kulevanova, S. (2014). Chemical characterization of Centaurium erythrea L. and its effects on carbohydrate and lipid metabolism in experimental diabetes. Journal of Ethnopharmacology, 152(1), 71-77. doi: http://doi.org/10.1016/j.jep.2013.11.047

5. Tuluce, Y., Ozkol, H., Koyuncu, I., Ine, H. (2011). Gastroprotective effect of small centaury (Centaurium erythraea L) on aspirininduced gastric damage in rats. Toxicology and Industrial Health, 27 (8), 760-768. doi: http://doi.org/10.1177/0748233710397421

6. Patel, M. B., Mishra, S. H. (2011). Hypoglycemic activity of C-glycosyl flavonoid fromEnicostemma hyssopifolium. Pharmaceutical Biology, 49 (4), 383-391. doi: http://doi.org/10.3109/13880209.2010.517759

7. El Menyiy, N., Guaouguaou, F.-E., El Baaboua, A., El Omari, N., Taha, D., Salhi, N. et. al. (2021). Phytochemical properties, biological activities and medicinal use of Centaurium erythraea Rafn. Journal of Ethnopharmacology, 276, 114171. doi: http://doi.org/10.1016/ j.jep.2021.114171 
8. Aberham, A., Pieri, V., Croom, E. M., Ellmerer, E., Stuppner, H. (2011). Analysis of iridoids, secoiridoids and xanthones in Centaurium erythraea, Frasera caroliniensis and Gentiana lutea using LC-MS and RP-HPLC. Journal of Pharmaceutical and Biomedical Analysis, 54 (3), 517-525. doi: http://doi.org/10.1016/j.jpba.2010.09.030

9. Boroduske, A., Nakurte, I., Tomsone, S., Lazdane, M., Boroduskis, M., Rostoks, N. (2016). In vitro culture type and elicitation affects secoiridoid and xanthone LC-ESI-TOF MS profile and production in Centaurium erythraea. Plant Cell, Tissue and Organ Culture (PCTOC), 126 (3), 567-571. doi: http://doi.org/10.1007/s11240-016-1016-3

10. Shikov, A. N., Pozharitskaya, O. N., Makarov, V. G., Wagner, H., Verpoorte, R., Heinrich, M. (2014). Medicinal Plants of the Russian Pharmacopoeia; their history and applications. Journal of Ethnopharmacology, 154 (3), 481-536. doi: http://doi.org/10.1016/ j.jep.2014.04.007

11. European Pharmacopoeia (2017). Strasbourg: European Directorate for the Quality of Medicines \& Health Care.

12. Sharma, M. K., Bachwani, M. (2013). Significance of Plant Bitters In The Field of Pharmacognosy. Asian Journal of Pharmaceutical Technology \& Innovation, 1 (3), 1-14.

13. Jaishree, V., Badami, S. (2010). Antioxidant and hepatoprotective effect of swertiamarin from Enicostemma axillare against dgalactosamine induced acute liver damage in rats. Journal of Ethnopharmacology, 130 (1), 103-106. doi: http://doi.org/10.1016/ j.jep.2010.04.019

14. Proskurova, Ya., Gubar, S., Kotova, E., Kotov, A., Datkhayev, U. (2017). Development of the method for Centaury herb identification by thin layer chromatography for the State Pharmacopoeia of Ukraine monograph. Bulletin of National Academy of sciences of the Republic of Kazakhstan, 2 (5), 5-12.

15. Proskurova, Y. A., Gubar, S. N., Kotova, E. E., Kotov, A. G. (2016). A comparative analysis of european and german pharmacopoeias requirements to the "bitterness value" test. ScienceRise, 4 (4 (21)), 65-68. doi: http://doi.org/10.15587/2313-8416.2016.67687

16. ICH harmonized tripartite guideline Q2(R1). Validation of analytical procedures: text and methodology Q2(R1) (2005). Proceedings of the International Conference on Harmonization of Technical Requirements for Registration of Pharmaceuticals for Human Use. Geneva. Available at: https://database.ich.org/sites/default/files/Q2 \%28R1 \%29 \%20Guideline.pdf

17. State Pharmacopoeia of Ukraine. Vol. 3 (2014). Kharkiv: State enterprise "Ukrainian scientific pharmacopoeial center of medicines quality".

18. Xiong, K., Gao, T., Zhang, T., Wang, Z., Han, H. (2017). Simultaneous determination of gentiopicroside and its two active metabolites in rat plasma by LC-MS/MS and its application in pharmacokinetic studies. Journal of Chromatography B, 10651066, 1-7. doi: http://doi.org/10.1016/j.jchromb.2017.09.017

19. Glatz, Z., Pospísilová, J., Musil, P. (2000). Determination of gentiopicroside in extracts of centaurium erythreae and gentiana lutea by micellar electrokinetic capillary chromatography. Journal of Liquid Chromatography \& Related Technologies, 23 (12), 1831-1839. doi: http://doi.org/10.1081/jlc-100100454

20. Xu, Y., Li, Y., Maffucci, K., Huang, L., Zeng, R. (2017). Analytical Methods of Phytochemicals from the Genus Gentiana. Molecules, 22 (12), 2080. doi: http://doi.org/10.3390/molecules22122080

21. Alam, P., Ali, M., Singh, R., Shakeel, F. (2009). Estimation of swertiamarin in Enicostemma littorale and marketed formulations using HPLC-UV Method. Journal of Bioanalysis and Biomedicine, 1 (1), 22-27.

22. Kshirsagar, P. R., Pai, S. R., Nimbalkar, M. S., Gaikwad, N. B. (2015). RP-HPLC analysis of seco-iridoid glycoside swertiamarin from differentSwertiaspecies. Natural Product Research, 30 (7), 865-868. doi: http://doi.org/10.1080/14786419.2015.1071366

23. Gubar, S. M., Materiienko, A. S., Smielova, N. M., Budanova, L. G., Georgiyants, V. A. (2020). Development of a New Approach for Standardization of the Herb Centaurium erythraea Rafn. by High Performance Liquid Chromatography. Turkish Journal of Pharmaceutical Sciences, 17 (6), 593-598. doi: http://doi.org/10.4274/tjps.galenos.2019.71542

24. Pataczek, L., Cheilari, A., Zikeli, S., Sturm, S., Stuppner, H., Gruber, S. (2017). Centaurium erythraea Cultivation Method for Optimal Yield and Product Quality. Journal of Herbs, Spices \& Medicinal Plants, 23 (3), 193-215. doi: http://doi.org/10.1080/10496475.2017.1295414

Received date 06.04.2021

Accepted date 27.05.2021

Published date 30.06.2021

Svitlana Gubar, PhD, Associate Professor, Department of Pharmaceutical Chemistry, National University of Pharmacy, Pushkinska str. 53, Kharkiv, Ukraine, 61002

Anna Materiienko*, PhD, Assistant, Department of Quality, Standardization and Certification of Drugs, National University of Pharmacy, Pushkinska str. 53, Kharkiv, Ukraine, 61002

Liudas Ivanauskas, Doctor of Biomedical Sciences, Professor, Head of Department, Department of Analytical and Toxicological Chemistry, Lithuanian University of Health Sciences, A. Mickevičiaus g. 9, Kaunas, Lithuania, LT-44307

Volodymyr Mishchenko, PhD, Associate Professor Department of Quality, Standardization and Certification of Drugs, National University of Pharmacy, Pushkinska str. 53, Kharkiv, Ukraine, 61002

Olha Vasylieva, $\mathrm{PhD}$, Associate Professor, Department of Quality, Standardization and Certification of Drugs, National University of Pharmacy, Pushkinska str. 53, Kharkiv, Ukraine, 61002

Victoriya Georgiyants, Doctor of Pharmaceutical Sciences, Professor, Head of Department, Department of Pharmaceutical Chemistry National University of Pharmacy, Pushkinska str., 53, Kharkiv, Ukraine, 61002

*Corresponding author: Anna Materiienko, e-mail: anna.materienko@gmail.com 